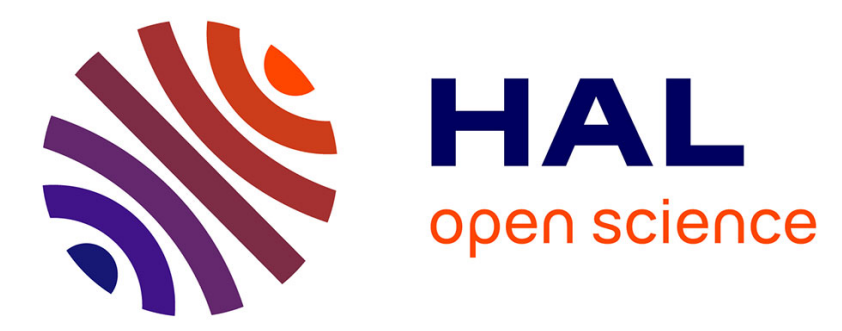

\title{
Intrinsic Variability of Sea Level from Global 1/12 degrees Ocean Simulations: Spatiotemporal Scales
}

Serazin Guillaume, T. Penduff, S. Gregorio, Bernard Barnier, J.-M. Molines, Laurent Terray

\section{- To cite this version:}

Serazin Guillaume, T. Penduff, S. Gregorio, Bernard Barnier, J.-M. Molines, et al.. Intrinsic Variability of Sea Level from Global 1/12 degrees Ocean Simulations: Spatiotemporal Scales. Journal of Climate, 2015, 28 (10), pp.4279-4292. 10.1175/JCLI-D-14-00554.1 . insu-01205199

HAL Id: insu-01205199

https://hal-insu.archives-ouvertes.fr/insu-01205199

Submitted on 25 Sep 2015

HAL is a multi-disciplinary open access archive for the deposit and dissemination of scientific research documents, whether they are published or not. The documents may come from teaching and research institutions in France or abroad, or from public or private research centers.
L'archive ouverte pluridisciplinaire $\mathbf{H A L}$, est destinée au dépôt et à la diffusion de documents scientifiques de niveau recherche, publiés ou non, émanant des établissements d'enseignement et de recherche français ou étrangers, des laboratoires publics ou privés. 


\title{
${ }^{\partial}$ Intrinsic Variability of Sea Level from Global $1 / 12^{\circ}$ Ocean Simulations: Spatiotemporal Scales
}

\author{
GUILLAUME SÉRAZIN \\ CNRS, LGGE (UMR5183), Grenoble, and, Sciences de l'Univers au CERFACS, CERFACS/CNRS, URA1857, \\ Université Paul Sabatier, Toulouse, France \\ Thierry Penduff, SAndy Grégorio, Bernard Barnier, and Jean-Marc Molines \\ CNRS, Université Grenoble Alpes, LGGE (UMR5183), Grenoble, France
}

LAURENT TERRAY

Sciences de l'Univers au CERFACS, CERFACS/CNRS, URA1857, Toulouse, France

(Manuscript received 28 July 2014, in final form 3 December 2014)

\begin{abstract}
In high-resolution ocean general circulation models (OGCMs), as in process-oriented models, a substantial amount of interannual to decadal variability is generated spontaneously by oceanic nonlinearities: that is, without any variability in the atmospheric forcing at these time scales. The authors investigate the temporal and spatial scales at which this intrinsic oceanic variability has the strongest imprints on sea level anomalies (SLAs) using a $1 / 12^{\circ}$ global OGCM, by comparing a "hindcast" driven by the full range of atmospheric time scales with its counterpart forced by a repeated climatological atmospheric seasonal cycle. Outputs from both simulations are compared within distinct frequency-wavenumber bins. The fully forced hindcast is shown to reproduce the observed distribution and magnitude of low-frequency SLA variability very accurately. The small-scale $\left(L<6^{\circ}\right)$ SLA variance is, at all time scales, barely sensitive to atmospheric variability and is almost entirely of intrinsic origin. The high-frequency (mesoscale) part and the low-frequency part of this small-scale variability have almost identical geographical distributions, supporting the hypothesis of a nonlinear temporal inverse cascade spontaneously transferring kinetic energy from high to low frequencies. The large-scale $\left(L>12^{\circ}\right)$ low-frequency variability is mostly related to the atmospheric variability over most of the global ocean, but it is shown to remain largely intrinsic in three eddy-active regions: the Gulf Stream, Kuroshio, and Antarctic Circumpolar Current (ACC). Compared to its $1 / 4^{\circ}$ predecessor, the authors' $1 / 12^{\circ}$ OGCM is shown to yield a stronger intrinsic SLA variability, at both mesoscale and low frequencies.
\end{abstract}

\section{Introduction}

The atmospheric and oceanic general circulations are barotropically and baroclinically (Eady 1949; Charney 1947) unstable and spontaneously generate geostrophic turbulence. In the ocean, this mesoscale turbulence emerges at the scale of $O(10-100) \mathrm{km}$ and $O(10-100)$ days and in turn strongly interacts with the general

๑ Denotes Open Access content.

Corresponding author address: Guillaume Sérazin, Laboratoire de Glaciologie et Géophysique de l'Environnement LGGE/CNRS, BP 96, 38402 Saint-Martin d'Heres, Grenoble, France.

E-mail: guillaume.serazin@legi.grenoble-inp.fr circulation (e.g., Holland 1978). Mesoscale turbulence is also a well-known, strong manifestation of intrinsic ocean variability (i.e., it emerges without any atmospheric variability) at relatively small time and space scales. Mesoscale turbulence is now (partly) resolved in many ocean general circulation model (OGCM) global simulations, as well as in several recent coupled climateoriented simulations. Bryan (2013) (and references therein) report various examples of how increases in OGCM resolution have substantially improved the fidelity of ocean simulations, and our understanding of

Publisher's Note: This article was revised on 10 June 2015 to correct a typographical error in the abstract where the wrong inequality was used, and to update the Grégorio et al. (2014) reference throughout the article to Grégorio et al. (2015). 
dynamical processes underlying the multiscale oceanic variability. Beyond the inclusion of mesoscale phenomena into the resolved spectrum, the transition from laminar $\left(1^{\circ}-2^{\circ}\right)$ to eddying $1 / 4^{\circ}$ and finer) OGCM resolutions also yields substantial modifications in the simulated variability at larger space and time scales. Comparing a series of global ocean-sea ice "hindcasts" at increasing resolution with observations, Penduff et al. (2010) showed how the transition from laminar to eddypermitting regimes brings the interannual variability of the ocean sea level much closer to altimeter measurements, in terms of both spatial distribution and of magnitude (increase of low-frequency variance larger than $60 \%$ over half of the global ocean).

Increasing resolution yields an increase in Reynolds number, which was also shown to favor the spontaneous emergence of low-frequency intrinsic variability (LFIV) in the ocean. Quasigeostrophic and shallow-water model experiments implemented on flat-bottom rectangular geometries have demonstrated that an interannual to decadal LFIV may appear under constant (or seasonal) forcing devoid of low frequencies and affect various components of the general circulation, in particular within the main unstable currents: strength and trajectory of surface and subsurface currents, intensity of recirculation gyres, thickness and volume of mode water pools, etc. (Spall 1996; Hazeleger and Drijfhout 2000; Simonnet and Dijkstra 2002; Dewar 2003; Pierini 2006; Berloff et al. 2007; Quattrocchi et al. 2012).

OGCM simulations tend to confirm these idealized predictions and illustrate various imprints of the LFIV in realistic contexts: path of oceanic jets (Taguchi et al. 2007; Thompson and Richards 2011; Douglass et al. 2012), subtropical mode waters (Douglass et al. 2013), eastern boundary circulation patterns (Combes and Di Lorenzo 2007), and larger-scale circulation features such as the Atlantic overturning circulation (Thomas and Zhai 2013; Grégorio et al. 2015, hereafter GPSH) or wide areas of the Southern Ocean (O'Kane et al. 2013). Penduff et al. (2011, hereafter P11) provided evidence that the strong increase in sea level anomaly (SLA) interannual variance, reported by Penduff et al. (2010) when switching from $2^{\circ}$ to $14^{\circ}$ resolution, may be related to the strong LFIV that emerges only in the eddying regime. This intrinsic component is indeed spontaneously produced by the same $1 / 4^{\circ}$ model without any interannual forcing.

Our experimental strategy remains similar to P11's: a global OGCM is first driven by an atmospheric forcing containing a broad range of time scales to produce a realistic hindcast and then by a yearly repeated climatological atmospheric seasonal cycle to isolate the intrinsic variability. The present study further investigates the contribution of intrinsic processes to the SLA variability in the global ocean and extends P11's work in three ways.
First, we highlight the spectral distribution of atmospherically forced and intrinsic SLA variabilities within highand low-frequency bands, at small and large spatial scales. Second, we are now using global simulations at $1 / 12^{\circ}$ resolution in complement to $\mathrm{P} 11$ 's $14^{\circ}$ simulations, providing us with the opportunity to assess the impact of model resolution on intrinsic variability. Finally, the present analysis is performed over a $42-\mathrm{yr}$ period instead of $12 \mathrm{yr}$.

Section 2 presents the model configurations and numerical experiments used in this study. The simulated low-frequency SLA variability is then compared to altimeter observations. Postprocessing and filtering methods are described in section 3 . In section 4 , we compare the spatial distributions of low-frequency SLA variabilities between both $1 / 12^{\circ}$ experiments at small $\left(<6^{\circ}\right)$ and large $\left(>12^{\circ}\right)$ spatial scales. Section 5 presents the sensitivity of intrinsic variability to the increase in resolution from $14^{\circ}$ to $1 / 12^{\circ}$. Conclusions are given in section 6 .

\section{Numerical simulations and assessment}

\section{a. Numerical simulations}

As done earlier by Taguchi et al. (2007), P11, and O'Kane et al. (2013), our approach consists in comparing two eddying global OGCM simulations with two different atmospheric forcings. Our first $1 / 12^{\circ}$ simulation (the socalled $T$ experiment) is driven by the full range of atmospheric time scales between 1958 and 2012. It is intended to simulate the total ocean variability, which combines the intrinsic and atmospherically forced components. Our second $1 / 12^{\circ}$ simulation (the $I$ experiment), driven during $85 \mathrm{yr}$ by a repeated climatological atmospheric seasonal cycle, isolates the low-frequency intrinsic variability that emerges without any low-frequency forcing. Note that the $1 / 4^{\circ}$ resolution climatological simulation described and studied in P11 has been reprocessed and will be compared to the $1 / 12^{\circ}$ resolution simulation in section 5 . This $1 / 4^{\circ} I$ experiment was conducted over $327 \mathrm{yr}$.

All the simulations were performed in the framework of the Drakkar project ${ }^{1}$ using the Nucleus for European Modeling of the Ocean (NEMO; Madec 2008) ocean/sea ice numerical model. The $1 / 12^{\circ}$ simulations use the ORCA12 configuration with NEMO version 3.4 , the $1 / 4^{\circ}$ simulation uses the ORCA025 configuration with NEMO2.3. The three simulations ${ }^{2}$ share the same 46-level vertical discretization, a partial cell representation

\footnotetext{
${ }^{1} \mathrm{http}: / /$ www.drakkar-ocean.eu

${ }^{2}$ The $1 / 12^{\circ} I$ and $T$ experiments are referred to as ORCA12GJM02 and ORCA12-MJM88 in the Drakkar database, respectively, and the $1 / 4^{\circ} I$ experiment is referred to as ORCA025MJM01.
} 
of topography, and a momentum advection scheme that conserves energy and enstrophy (Barnier et al. 2006; Penduff et al. 2007; Le Sommer et al. 2009); a total variance diminishing (TVD) tracer advection scheme; an isopycnal Laplacian tracer diffusion operator; a vertical mixing scheme based on the TKE turbulent closure model (Blanke and Delecluse 1993); and a convective adjustment scheme based on enhanced vertical mixing in case of static instability.

The full and climatological forcing functions used to drive the $1 / 12^{\circ}$ simulations come from the same original forcing dataset, which is referred to as the Drakkar forcing set (DFS4.4; Dussin and Barnier 2013); this 1958-2012 dataset is based on satellite observations (monthly precipitations and daily radiative heat fluxes) and on ERA-40 before 31 December 2001 and ERAInterim afterward (6-hourly 10-m air temperature, humidity, and winds). ${ }^{3}$ The method we used to derive the climatological forcing from the full forcing is described in P11, who demonstrated (see also GPSH) that both forcing functions yield very similar mean states. Our $1 / 12^{\circ}$ simulations are described in detail in Molines et al. (2014). Note that the seasonally forced $1 / 12^{\circ}$ simulation has been analyzed in Treguier et al. (2014) and Deshayes et al. (2013) and that our pair of $1 / 12^{\circ}$ simulations is also used by GPSH. The $327-\mathrm{yr} 1 / 4^{\circ}$ climatological simulation to which we compare the $1 / 12^{\circ} I$ experiment in section 5 is presented in detail in P11. It was reprocessed exactly as its $1 / 12^{\circ}$ counterpart (see section 3 ). More information about model configurations and solutions may be found in the aforementioned papers.

\section{b. Model assessment}

Archiving, Validation, and Interpretation of Satellite Oceanographic Data (AVISO) provides us with $20 \mathrm{yr}$ of global altimeter observations on a $14^{\circ} \times 1 / 4^{\circ}$ regular Cartesian grid. ${ }^{4}$ Our fully forced, $1 / 12^{\circ}$ global hindcast is first compared to this reference over the period July 1994-July 2011 in terms of low-frequency SLA standard deviation. We use monthly-mean, nonlinearly detrended, low-pass filtered (periods longer than 18 months) SLA fields to compute low-frequency SLA standard deviations

\footnotetext{
${ }^{3}$ DFS4.4 differs from DFS4 (Brodeau et al. 2010) only after 31 December 2001, where ERA-Interim is used instead of the ECMWF analysis for all forcing variables: wind vector, air temperature and humidity, downward shortwave and longwave radiation, total precipitation, and snowfall. Corrections described in Brodeau et al. (2010) ensure a smooth transition in 2001-02. ERAInterim variables, whose native resolution is $0.7^{\circ}$ and $3 \mathrm{~h}$, were projected at the ERA-40 resolution $\left(1.125^{\circ}\right.$ and $\left.6 \mathrm{~h}\right)$ to build DSF4.4. Note that DFS4 was also compared with the more widely used CORE.v2 forcing in the latter reference.

${ }^{4}$ http://www.aviso.altimetry.fr/duacs/
}

from both AVISO and the $1 / 12^{\circ} T$ experiment; the postprocessing method is detailed in the next section. Figure 1 demonstrates the capability of the $1 / 12^{\circ}$ model to simulate the SLA low-frequency variability field with a remarkable accuracy. The location and intensity of the low-frequency variability in western boundary currents and their extension are well reproduced. Equatorial low-frequency activity is found in the same locations with comparable intensities in the observed and simulated oceans. The simulated path of the Antarctic Circumpolar Current variability maximum is close to that derived from altimetric observations. The $1 / 12^{\circ}$ hindcast therefore yields a very realistic low-frequency variability field; it may be fruitfully analyzed, jointly with its climatologically forced counterpart, to characterize the intrinsic part of the lowfrequency variability measured by altimetry.

\section{Postprocessing and scale separation}

\section{a. Separating temporal scales}

The first years of model spinup are discarded from our analyses. Comparisons between the $1 / 12^{\circ}$ simulations are performed from successive monthly sea surface height ( $\mathrm{SSH})$ averages over the same duration (47 yr): that is, over the period 1966-2012 from the $T$ experiment and years 16-62 from the $I$ experiment. The postprocessing of simulated SSH fields starts with the removal of global spatial averages from each monthly map (see Greatbatch 1994; P11). The resulting time series $\eta(t)$ may then be split as

$$
\eta(t)=\bar{\eta}+\tilde{\eta}(t)+\eta^{s}(t)+\eta^{L F}(t)+\eta^{H F}(t)
$$

at every grid point, where $\bar{\eta}$ denotes the time average, $\tilde{\eta}$ is the long-term trend, $\eta^{s}$ is the mean annual cycle, $\eta^{\mathrm{LF}}$ is the low-frequency (LF; interannual and slower) variability, and $\eta^{\mathrm{HF}}$ is the high-frequency (HF; subannual) variability. Our study is focused on the intrinsic high- and low-frequency variabilities; time averages are removed first.

- Long-term trends $\tilde{\eta}(t)$ denote very low-frequency signals that need to be removed from raw time series to avoid biases in variance analyses. These trends may be of two kinds. The first kind is related to model adjustment toward its final equilibrium state, which may take a few centuries. This signal is unavoidable in OGCM simulations because of uncertainties that include those in atmospheric forcing, initial states, and physical and numerical approximations. However, it is small compared to the actual (well resolved) temporal variability. The second kind of trend may appear in finite-length time series when signals with periods longer than the time series itself are present. Both kinds of trends may yield a linear or nonlinear $\tilde{\eta}(t)$ 


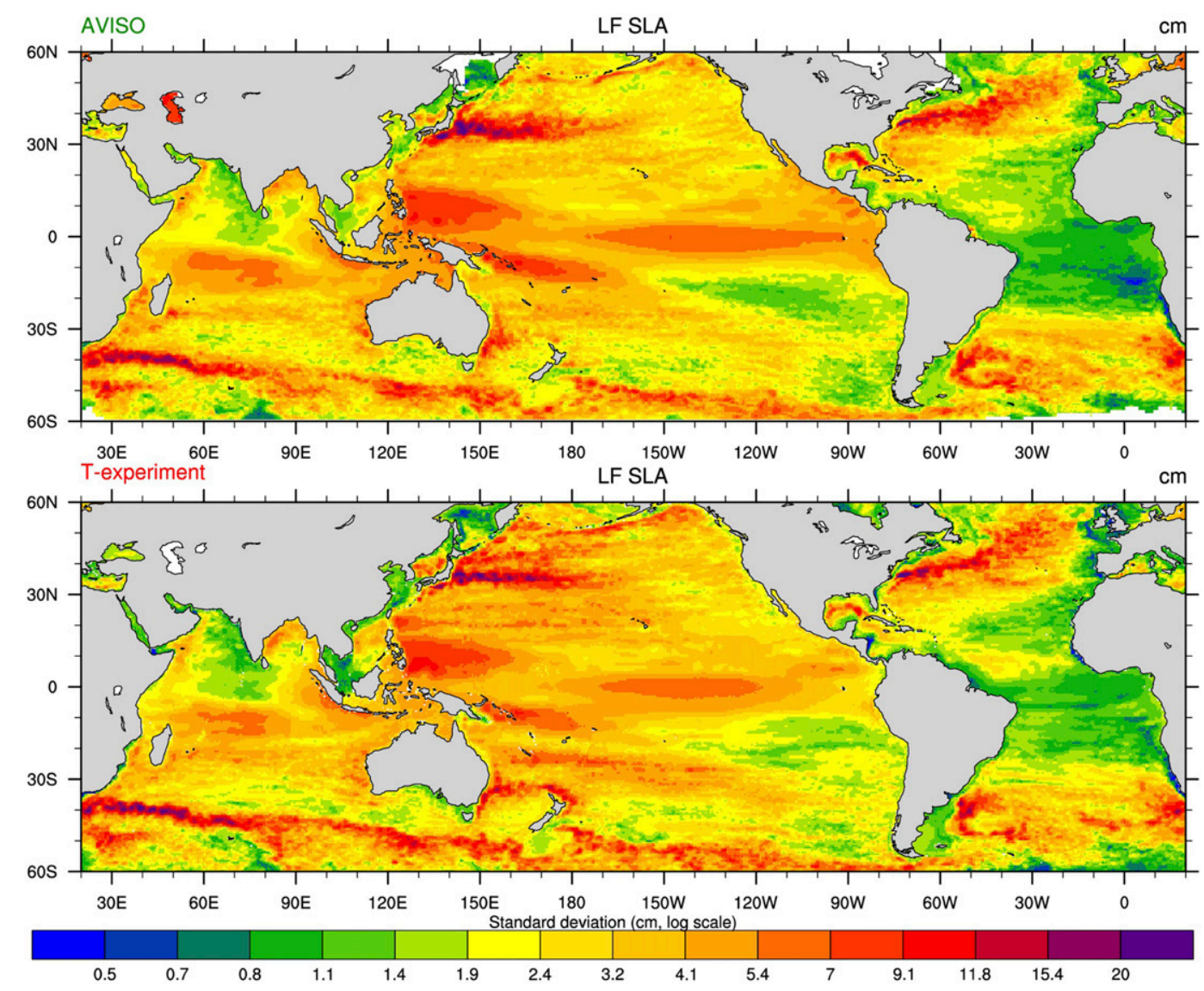

FIG. 1. Low-frequency ( $T>18$ months) SLA standard deviations computed over the period July 1994-July 2011 from (top) the $1 / 4^{\circ}$ AVISO dataset and (bottom) the $1 / 12^{\circ} T$ experiment.

evolution over the length of the time series. Our detrending approach is based on a nonlinear, second-order local regression method (LOESS; Cleveland and Devlin 1988), which high-pass filters model time series with a 20 -yr cutoff period. This method preserves the length of original time series without adverse edge effects (Fig. 2). Our cutoff period ensures the removal of both kinds of trends, and confines our analyses and results on time scales between 2 months and $20 \mathrm{yr}$ in both simulations.

- The mean annual cycle $\eta^{s}(t)$ is then computed from SLA time series and subtracted to obtain deseasonalized, detrended SLA time series.

- The low- and high-frequency $\left[\eta^{\mathrm{LF}}(t)\right.$ and $\eta^{\mathrm{HF}}(t)$, respectively] variabilities are then isolated from the time series resulting from the former steps. Following P11, our low-frequency signals include time scales longer than 18 months. Unlike these authors, however, our highfrequency signals include time scales ranging between 2 and 18 months, with no mean annual cycle. Low- and high-frequency components are separated using a Lanczos temporal filter (Duchon 1979), chosen for its efficiency and its ability to provide clean signals with small Gibbs oscillations. Note that this is a linear filtering method and it has edge effects because of the fixed size of the convolution kernel (relative to the filter order). Thus, $3 \mathrm{yr}$ on both extremities of the time series are lost in this computation, yielding lowand high-frequency 41 -yr time series from both $1 / 12^{\circ}$ runs: years 1969-2009 in the $T$ experiment and years $19-59$ in the $I$ experiment.

\section{b. Separating spatial scales}

The main purpose of this paper is to document how intrinsic processes contribute to the total SLA variability in various wavenumber-frequency $(\kappa-\omega)$ classes. High- and low-frequency datasets are further split into three ranges of spatial scales by applying a twodimensional, isotropic Lanczos low-pass filter twice with different cutoff lengths. We shall focus in the following on structures shorter than about $6^{\circ}$ [labeled as small scales (SS)] and structures larger than about $12^{\circ}$ [large scales (LS)]. Structures with sizes between $6^{\circ}$ and 


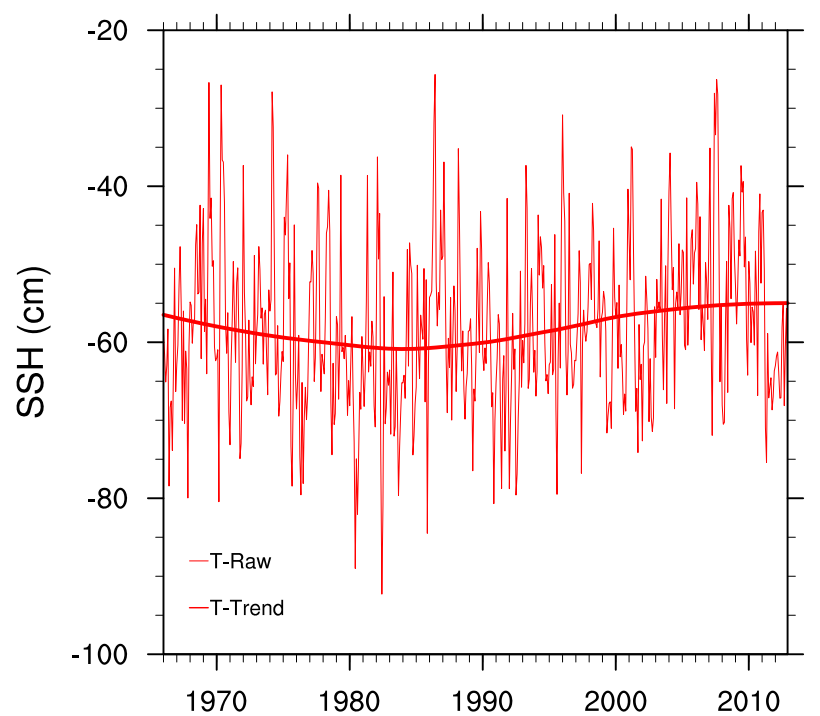

FIG. 2. Example of the nonlinear trend calculated (thick line) from a $42-\mathrm{yr}$ time series of SLA at $\left(52.5^{\circ} \mathrm{N}, 179^{\circ} \mathrm{W}\right)$ in the ACC (thin line) obtained in the $T$ experiment.

$12^{\circ}$ are also produced during the filtering process but are not investigated here. Motivations leading to $6^{\circ}$ and $12^{\circ}$ are similar to those given in Penduff et al. (2010) and Taguchi et al. (2007).

In practice, the spatial cutoffs are defined in terms of model grid points rather than distances: hence, the approximate scales mentioned above. The spatial filter is adapted to process SLA fields in the vicinity of land points (islands and coasts): the kernel coefficients used in the convolution are weighted to take into account only wet points. To limit computational costs, the size of the convolution kernel was kept the same in both spatial filtering processes: this size is close to four $6^{\circ}$ wavelengths and two $12^{\circ}$ wavelengths. The $6^{\circ}$ filter is therefore more selective than the $12^{\circ}$ filter.

In summary, the postprocessing chain described in section 3 decomposes the (detrended) total and intrinsic variabilities within six main $\kappa-\omega$ bands (as summarized in Fig. 3). Figure 4 illustrates three steps of this processing in November 1997: detrended monthly SLA fields after temporal low-pass filtering (top panels) and after further splitting into small and large scales (middle and bottom panels). Note that the high-frequency smallscale (HFSS) variability will also be referred to as mesoscale because geostrophic turbulence is found in this spectral domain.

\section{Spatial scales of intrinsic SLA variability}

We focus first on the LF component of SLA variabilities in both model experiments, taking all spatial scales into account. Figure 5 (top) compares in zonal

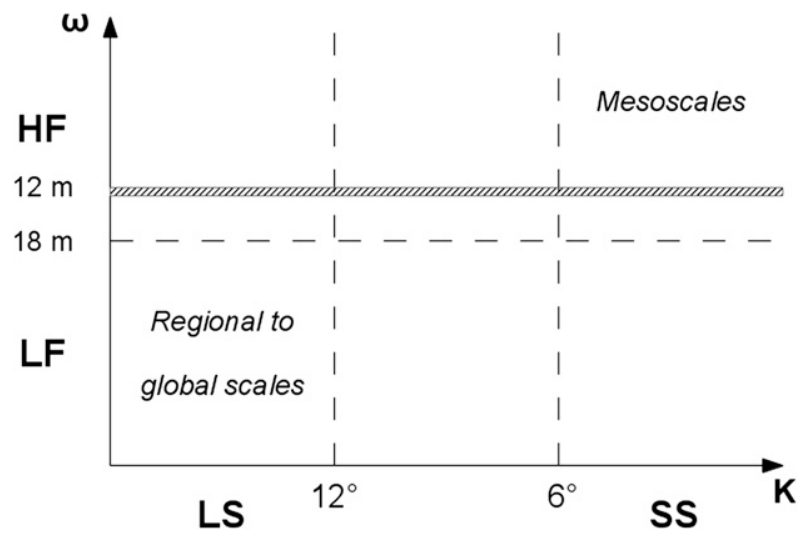

FIG. 3. Filter cutoffs in the wavenumber-frequency $(\kappa-\omega)$ space. The hatched horizontal bar at 12 months indicates that the mean annual cycle harmonics were removed from high-frequency fields.

average their meridional distributions. The total (fully forced) SLA low-frequency standard deviation remains within $3-4 \mathrm{~cm}$ over most of the $60^{\circ} \mathrm{S}-60^{\circ} \mathrm{N}$ latitudinal range, with absolute maxima at midlatitudes and minima poleward of $60^{\circ}$ in both hemispheres. Its intrinsic counterpart exhibits a marked contrast between lowlatitude and midlatitude areas. Both the intrinsic SLA low-frequency variability and its relative contribution $\sigma_{I}^{2} / \sigma_{T}^{2}$ reach their absolute minima in the intertropical band (less than $1 \mathrm{~cm}$ and $10 \%$, respectively, between $10^{\circ} \mathrm{S}$ and $10^{\circ} \mathrm{N}$ ) and their absolute maxima at midlatitudes in both hemispheres. Poleward of $60^{\circ} \mathrm{N}$ the intrinsic low-frequency variance reaches its secondary minima; most of the SLA variance there is therefore related to the low-frequency atmospheric variability in the $T$ experiment.

\section{a. Small-scale intrinsic variability}

The resemblance between the blue lines in the top and middle panels of Fig. 5 illustrates the importance of small-scale features in the distribution of intrinsic low-frequency variability; this section is focused on this low-frequency small-scale (LFSS) intrinsic variability. Low-frequency small-scale sea level anomalies have very similar distributions and amplitudes with or without atmospheric variability (middle panels in Figs. 4 and 5). The LFSS SLA variability is therefore largely intrinsic: that is, spontaneously produced by the eddying ocean over most regions (bottom panel in Fig. 6). ${ }^{5}$ This result is consistent with Taguchi et al. (2007), who showed that the structure of the

\footnotetext{
${ }^{5}$ The few exceptions to this concerns regions where LFSS variance is very weak $(\sigma<0.5 \mathrm{~cm})$ : that is, in shallow areas and equatorial basins.
} 

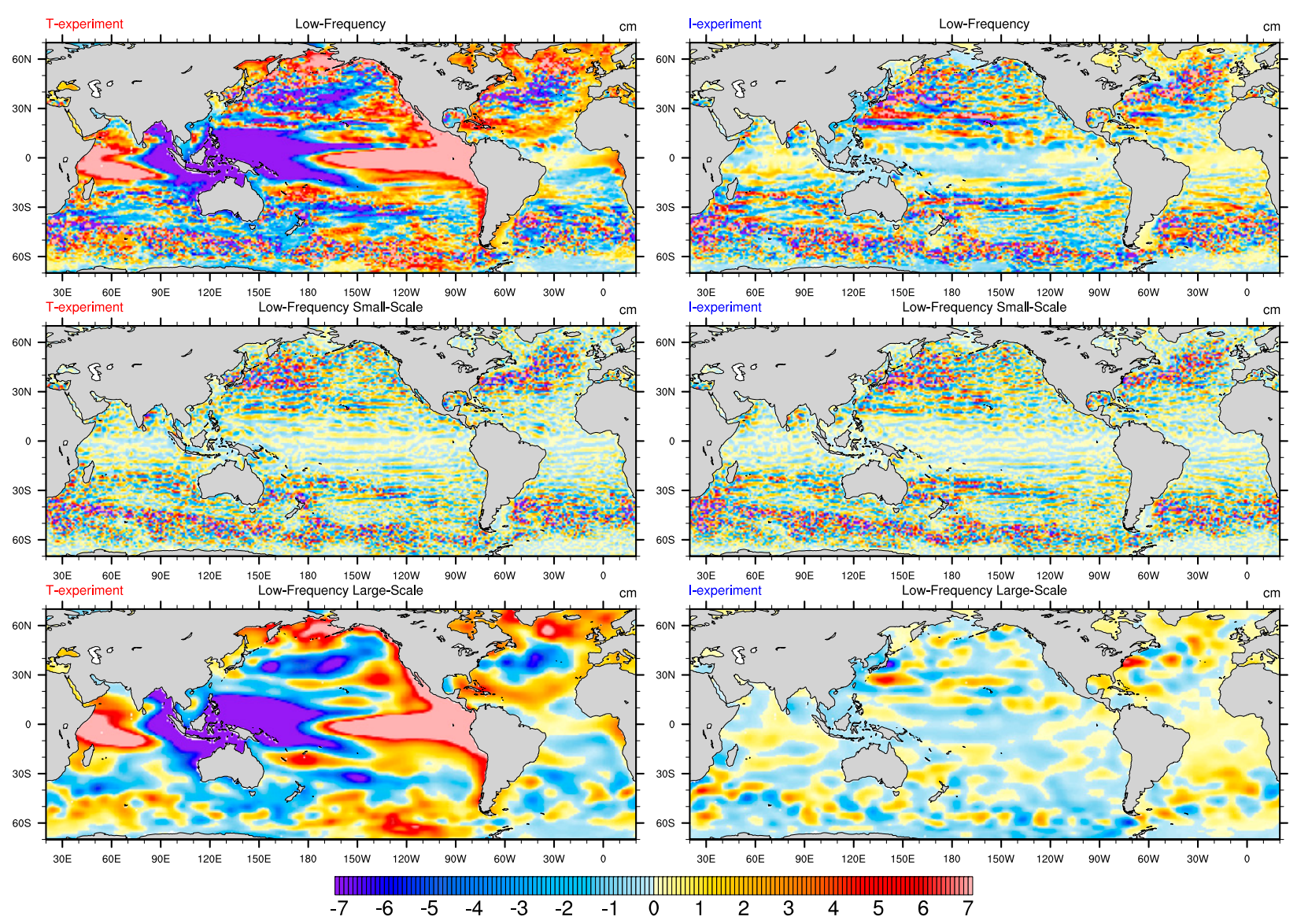

FIG. 4. SLA global maps on November 1997 from the (left) $T$ and (right) $I$ experiments in the low-frequency range: (top) containing all spatial scales, (middle) restricted to small spatial scales $\left(L<6^{\circ}\right)$, and (bottom) restricted to large-scale signals only $\left(L>12^{\circ}\right)$.

interannually varying Kuroshio has small (meridional) scales and is shaped by purely oceanic processes (i.e., identical with and without low-frequency forcing). A similar conclusion was drawn in the Southern Ocean by O'Kane et al. (2013), who showed that small-scale low-frequency modulations of the Antarctic Circumpolar Current (ACC) are captured in both fully forced and climatological simulations. Intrinsic, interannual fluctuations of sea level can largely be explained by mesoscale processes in the Gulf of Alaska as well (Okkonen et al. 2001; Combes and Di Lorenzo 2007). In other words, the bottom panel in Fig. 6 suggests that the conclusions of these regional studies may well be valid over most of the global ocean.

As recalled in the introduction, mesoscale eddies emerge through hydrodynamic instability processes at small space and time scales. These motions are captured in our HFSS spectral box, and their (intrinsic) standard deviation in the $I$ experiment is shown in the top panel of Fig. 7. This map is very close to its counterpart in the $T$ experiment (not shown), confirming that most HFSS (mesoscale) activity is generated through intrinsic processes and is barely sensitive to low-frequency atmospheric variability.

Interestingly, large values of LFSS intrinsic variability are found where mesoscale eddies are strong (Fig. 6): that is, in the ACC, East Australian Current, Brazil Current/Malvinas Confluence region, Agulhas Current, Kuroshio, and Gulf Stream/North Atlantic Current systems. Indeed, LFSS and HFSS intrinsic variability maps (Figs. 6 and 7) are very similar: the bottom panels in Fig. 7 show that SLA standard deviations in both spectral ranges have similar meridional distributions (left) and are highly correlated in space. These results are consistent with the spontaneous emergence of mesoscale eddies through (intrinsic) instability processes in both simulations, with only a weak sensitivity to atmospheric variability. The marked coincidence between HFSS and LFSS intrinsic variability maps suggests that the energy of these mesoscale motions may spontaneously cascade toward longer time scales and feed the LFSS spectral component. Such a temporal inverse cascade has indeed been diagnosed recently from idealized and realistic simulations (Arbic et al. 2012, 2014), albeit 

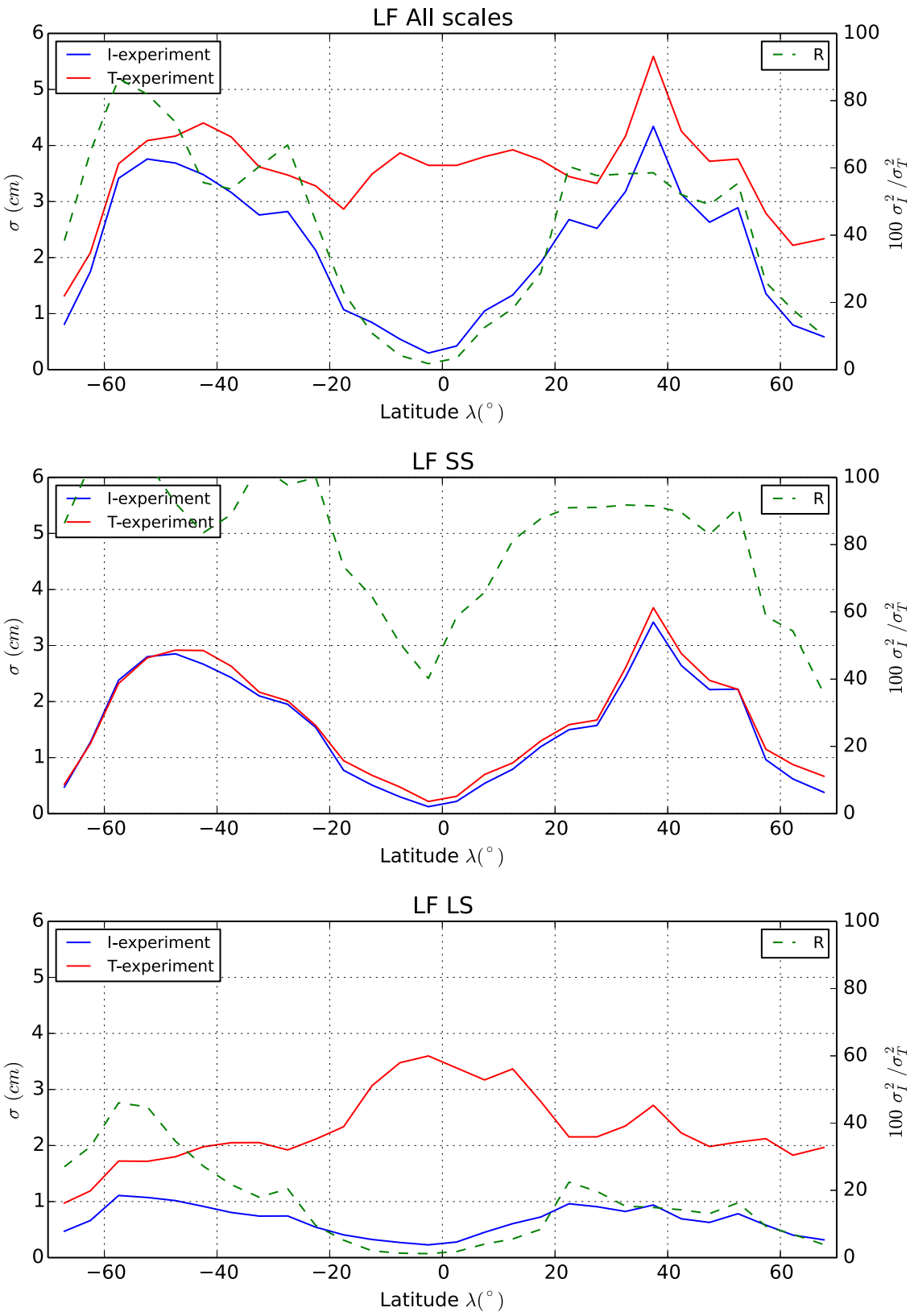

FIG. 5. Zonal average of total (red) and intrinsic (blue) low-frequency standard deviations: (top) all spatial scales, (middle) small scales, and (bottom) large scales. Corresponding intrinsic to total variance ratios are shown (right $y$ axis in \%) in green in each panel.

over a narrower range of time scales. Whether this nonlinear process may actually transfer mesoscale kinetic energy up to interannual and longer time scales remains to be assessed and is currently being investigated.

\section{b. Large-scale low-frequency intrinsic variability}

The bottom panels in Fig. 4 indicate that strong lowfrequency large-scale SLAs, which are hindcasted in the $T$ experiment (strong El Niño event, Indian Ocean dipole, and Pacific decadal oscillation positive phases in November 1997), are not spontaneously generated by the eddying ocean; they require direct forcing by the atmosphere (or full air-sea coupling) to exist. The zonally averaged LFLS SLA variability is indeed much stronger with the full forcing over most of the global ocean (Fig. 5), especially in the intertropical band, where SLA intensities reach their global maximum in the $T$ experiment and their global minimum in the $I$ experiment. 



FIG. 6. Low-frequency small-scale (top) total and (middle) intrinsic standard deviations. (bottom) Intrinsic to total variance ratio in the same range of scales.

In western boundary current extensions and in the ACC, however, our $1 / 12^{\circ}$ model spontaneously generates low-frequency large-scale SLA anomalies with small but nonnegligible zonally averaged intensities (bottom-right panel in Fig. 4 and bottom panel in Fig. 5). LFLS intrinsic variability is strongest in eddy-active regions (middle panel in Fig. 8): that is, where small-scale standard deviations were proven largest (HFSS and LFSS bands). The geographical correspondence between these three spectral maxima further suggests that 

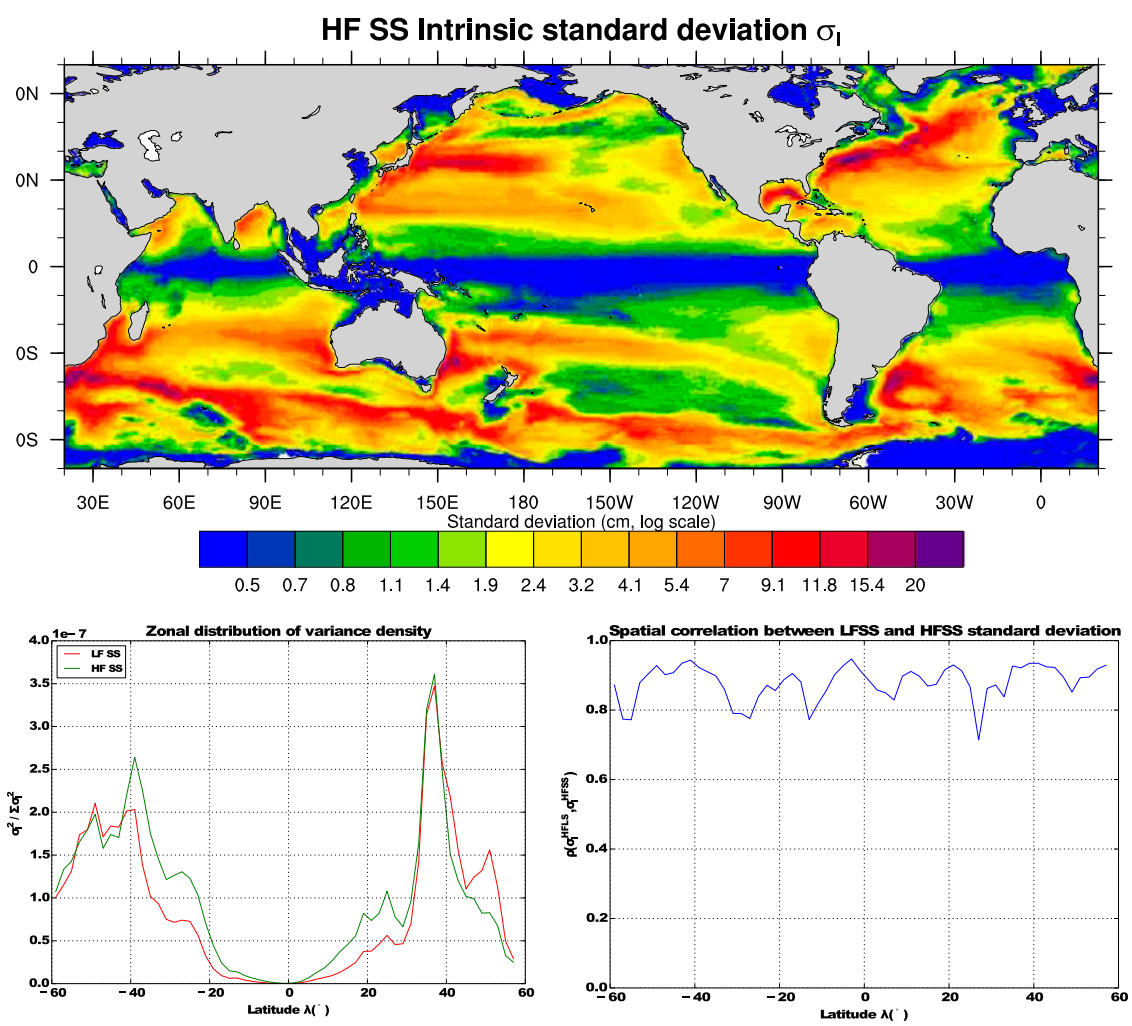

FIG. 7. (top) High-frequency small-scale intrinsic variability. (bottom left) Normalized distributions of intrinsic variances (zonal averages) as a function of latitude at LFSS (red) and HFSS (green). (bottom right) The spatial correlation of these latter two fields as a function of latitude.

intrinsic, eddy-driven inverse cascade processes may be transferring mesoscale (HFSS) kinetic energy toward larger temporal (LFSS) and spatial (LFLS) scales (e.g., Berloff et al. 2007; Arbic et al. 2014).

The contribution of intrinsic processes to the fully forced, low-frequency large-scale SLA variance is therefore substantial in several regions (bottom panel in Fig. 8): it exceeds $30 \%$ over wide regions of the Northern Hemisphere and reaches $40 \%$ in zonal average around $50^{\circ} \mathrm{S}$, with local maxima near $100 \%$ in Drake Passage, the Brazil Current/Malvinas Confluence, and the Agulhas Current.

\section{Influence of model resolution}

P11 presented an analysis of the low-frequency intrinsic variability from a seasonally forced simulation at $1 / 4^{\circ}$. This eddy-permitting simulation has been reprocessed in the same manner as was our $1 / 12^{\circ}$ simulations in order to assess the influence of model resolution on intrinsic variability. The comparison is based on SLA standard deviations computed over $36 \mathrm{yr}$ from both simulations.

\section{a. Increase in mesoscale variability}

Increasing resolution from $1 / 4^{\circ}$ to $1 / 12^{\circ}$ is known to strongly enhance the strength of simulated mesoscale activity in NEMO as well in other models (e.g., Hurlburt et al. 2009). Indeed, the zonally averaged HFSS SLA variability, which is largely intrinsic as mentioned earlier, markedly increases as resolution is refined at midlatitudes and in the ACC belt (top panel in Fig. 9). The top panel in Fig. 10 shows that this increase in intrinsic, mesoscale SLA standard deviation reaches up to $2 \mathrm{~cm}$ in most regions poleward of $10^{\circ}-15^{\circ}$. Increased resolution, however, yields less mesoscale activity in the vicinity of the Kuroshio and Gulf Stream extensions and the ACC. Most of these local decreases are actually due to the displacement of energetic fronts and associated recirculation gyres and eddy fields, toward a more realistic mean state in the $1 / 12^{\circ}$ model.

\section{b. Increase in low-frequency intrinsic variability}

Increased resolution does not only enhance mesoscale turbulence. The bottom panel in Fig. 9 shows a concomitant increase in low-frequency intrinsic SLA standard deviation at all spatial scales. This increase occurs in regions where mesoscale activity is enhanced by the resolution increase, not only in zonal average but also at regional and frontal scales (Figs. 9 and 10). This tight geographical correspondence between changes in 

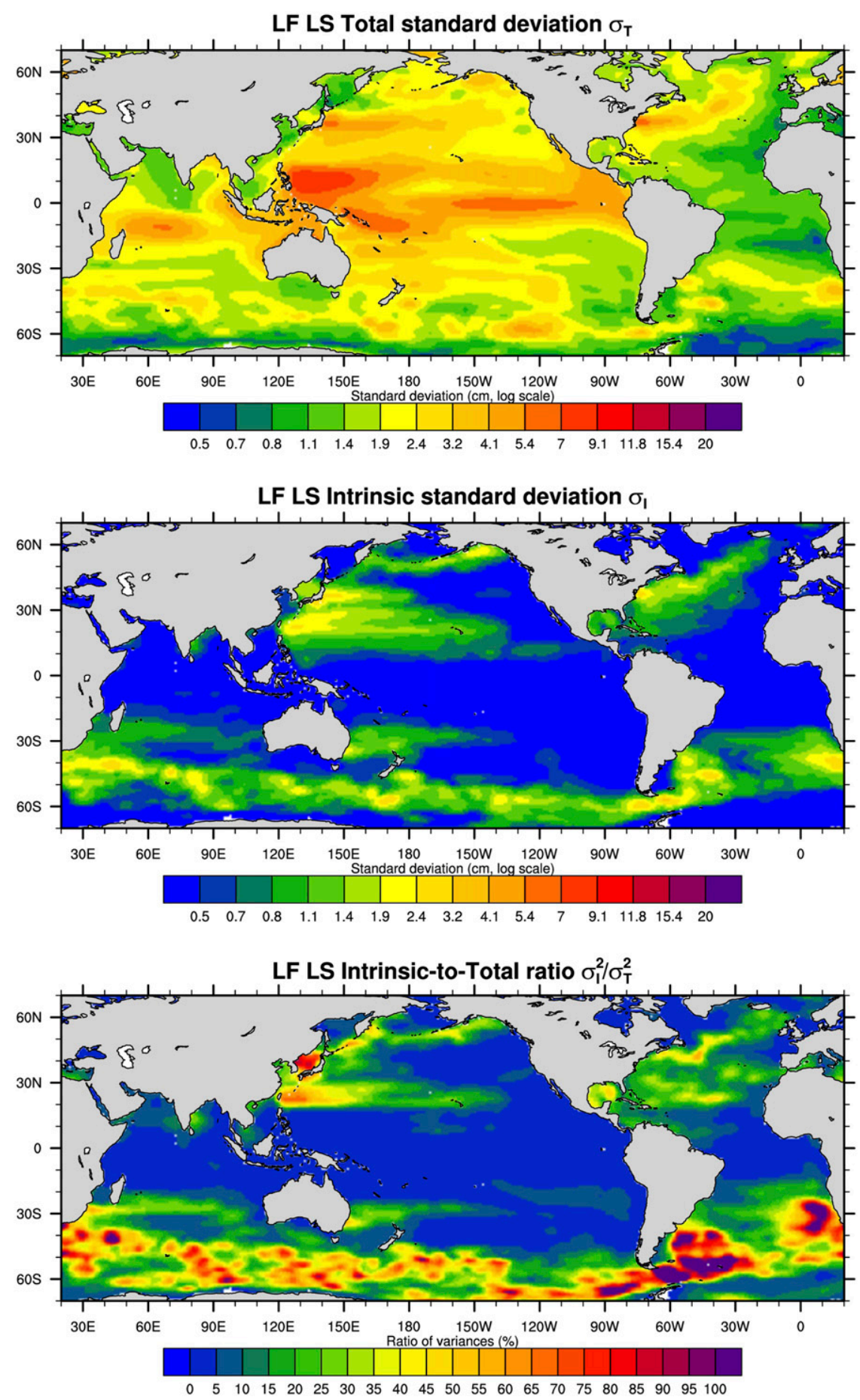

FIG. 8. As in Fig. 6, but at LFLS scales.

mesoscale and LF intrinsic variability was also striking at $1 / 12^{\circ}$ (Fig. 7) and further supports the idea that LF intrinsic variability may be directly fed by mesoscale activity through nonlinear temporal inverse cascade processes, both within and farther away from eddyactive regions.
Interestingly, GPSH are showing from the same simulations that in contrast with SLA, most of the intrinsic LF variability diagnosed at $1 / 12^{\circ}$ is captured at $1 / 4^{\circ}$ with respect to the Atlantic meridional overturning streamfunction (AMOC). This shows that a $14^{\circ}$ ocean model that somewhat underestimates local intrinsic variability 

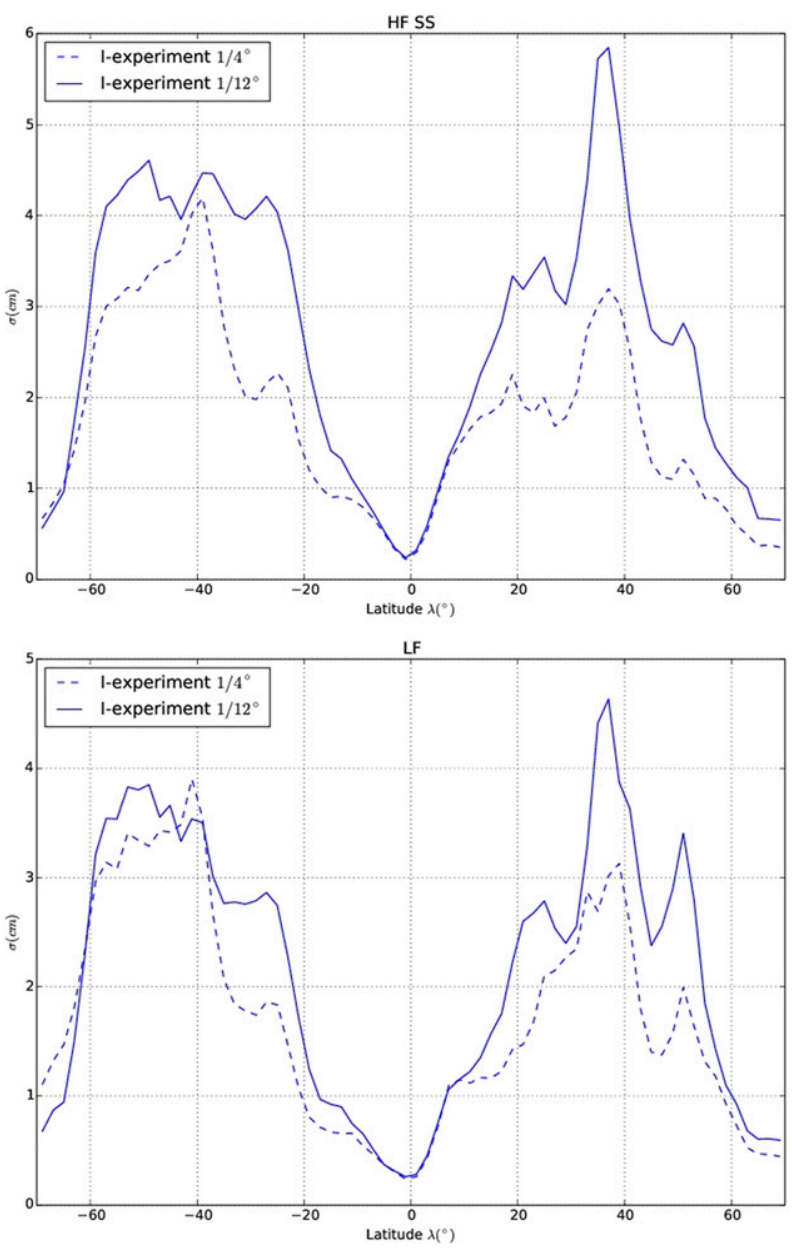

FIG. 9. Zonally averaged intrinsic standard deviation of SLA (cm) at $1 / 4^{\circ}$ (solid) and $1 / 12^{\circ}$ (dashed) at (top) HFSS and (bottom) LF for all scales.

imprints on SLA may yet capture the main processes generating intrinsic variability of the important climaterelated, large-scale oceanic index of the AMOC. Possible reasons for this remain to be identified.

\section{Conclusions}

The intrinsic variability that eddying ocean models spontaneously generate has been analyzed through its imprint on sea level anomalies at various scales. The NEMO-based $1 / 12^{\circ}$ ORCA12 global OGCM configuration was driven by the full range of atmospheric time scales ("hindcast" simulation) and then by a repeated atmospheric annual cycle (climatological simulation). Resulting SLA fields have been deseasonalized, filtered, and compared in three spatiotemporal ranges: the high-frequency small-scale (HFSS) range $(T<18$ months, $L<6^{\circ}$ ), which includes mesoscale turbulence; the low-frequency small-scale (LFSS) range $(T>18$ months, $L<6^{\circ}$ ); and the low-frequency large-scale (LFLS) range ( $T>18$ months, $L>12$ ). The hindcast was shown to reproduce the distribution and magnitude of low-frequency ( $T>18$ months) variability observed by satellite altimetry with a high degree of accuracy.

- Just as for mesoscale activity, most of the LFSS SLA variability is spontaneously generated by the eddying ocean with only weak sensitivity to the atmospheric variability. Regions of strong mesoscale variability closely coincide with regions where LFSS variability is large. This coincidence suggests that mesoscale energy may spontaneously cascade toward longer time scales through nonlinear processes, as recently suggested by Arbic et al. (2014).

- Most of the LFLS SLA variability is forced by the atmosphere in our simulations, in particular at low latitudes and in eastern basins. In eddy-active regions, however, intrinsic processes generate an important part of this large-scale low-frequency SLA variance: from $30 \%-50 \%$ in western boundary current systems up to $90-100 \%$ where the South Atlantic connect with surrounding basins.

- Decreasing the model resolution from $1 / 12^{\circ}$ to $1 / 4^{\circ}$ yields a decrease of both mesoscale and low-frequency intrinsic SLA variance, along with displacements of certain main currents. The $1 / 4^{\circ}$ low-frequency intrinsic variability distribution, however, remains comparable with its $1 / 12^{\circ}$ counterpart, suggesting that generation processes are reasonably well captured in the eddypermitting regime.

Many features of the intrinsic low-frequency variability remain unknown. Our results could be complemented by two- or three-dimensional, possibly multivariate, characterizations of intrinsic modes of variability in various regions [e.g., as done in the Southern Ocean by O'Kane et al. (2013)]. Of particular interest would be a precise description of how intrinsic variability imprints sea surface temperature or upper-ocean heat content at low frequencies, given the sensitivity of the atmospheric variability to these thermal constraints at long time scales (Gulev et al. 2013; Brachet et al. 2012). Current investigations are indeed highlighting substantial SST imprints where intrinsic variability imprints SLA.

The mechanisms that generate intrinsic lowfrequency variability in complex OGCM simulations also remain under debate. Based on 5-yr SLA time series, simulated by a global eddying OGCM driven by a full forcing, Arbic et al. (2014) showed that nonlinear eddy-eddy interactions can spontaneously transfer kinetic energy from mesoscale eddies, which are largely chaotic, to longer time scales. In other words, this 

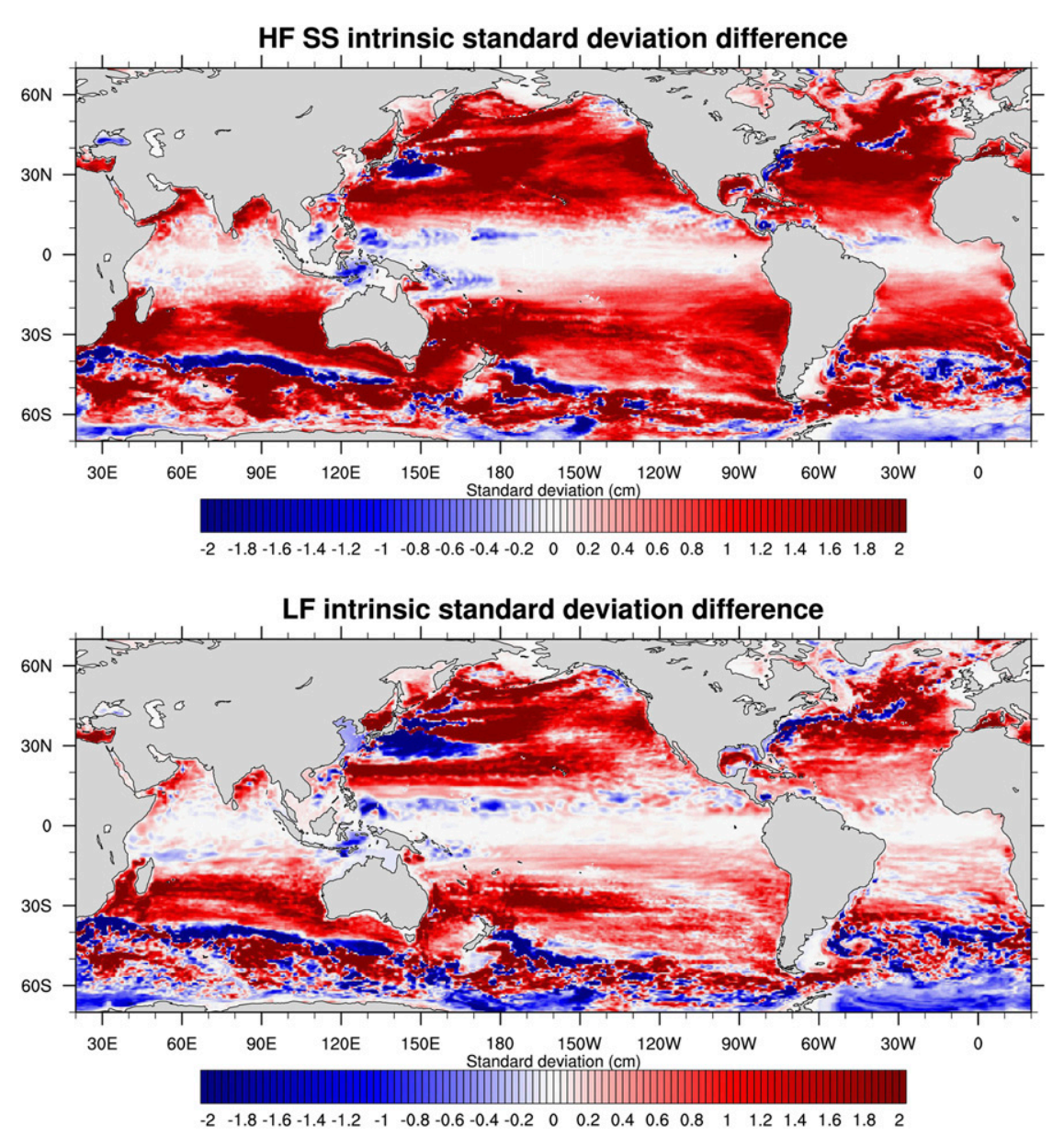

FIG. 10. Difference $\left(\sigma_{I}^{1 / 12}-\sigma_{I}^{1 / 4} ; \mathrm{cm}\right)$ of intrinsic standard deviation of SLA between $1 / 12^{\circ}$ and $1 / 4^{\circ}$ simulations, at (top) HFSS and (bottom) LF. The $1 / 12^{\circ}$ field has been subsampled on the $1 / 4^{\circ}$ grid.

temporal inverse cascade process might well transfer the mesoscale intrinsic chaotic variability toward lower frequencies. This analysis is currently being extended to much longer (multidecadal) SLA time series provided by our seasonally forced $1 / 4^{\circ}$ and $1 / 12^{\circ} I$ experiments, in order to assess whether the same mechanism may actually generate intrinsic variability up to decadal (or possibly longer) time scales. Note that very little is known today about the oceanic intrinsic variability at very long time scales (i.e., at multidecadal or longer periods). GPSH have recently shown from the full $327-y r$ $1 / 4^{\circ} I$ experiment that the AMOC spontaneously fluctuates up to such time scales; assessing the possible imprint of these processes on SLA, other variables, and climate indices remains to be done.

We have focused on the scales of the low-frequency intrinsic variability that spontaneously emerges without low-frequency forcing. The behavior of intrinsic variability modes in fully forced simulations (with lowfrequency forcing)—and more generally the actual constraint exerted by the atmospheric forcing on regions where this intrinsic variability is strong-is another important (and complex) issue. The Kuroshio system is already known to exhibit intrinsic modes of variability, which might be triggered by the low-frequency atmospheric forcing when present (Taguchi et al. 2007). This phenomenon has been studied in the framework of dynamical system theory with process-oriented idealized models; results show that stochastic forcings (Pierini 2011) or slowly varying forcings (Pierini 2014) could excite and lead to the resonance of intrinsic modes that are not spontaneously generated under a constant wind forcing. Whether this process is at work and dominates in complex OGCM simulations is still unknown and would deserve further investigations that we leave for the future; multiple high-resolution OGCM simulations, such as those performed in idealized contexts, or ensemble simulations would help address this question.

Finally, our ocean/sea ice simulations were forced by prescribed atmospheres. This decoupled approach, 
inspired from several idealized studies (e.g., reviewed in Dijkstra and Ghil 2005), allows the isolation and investigation of the intrinsic variability itself, ignoring its interaction with the atmosphere. Our results may help interpret how the transition from laminar to eddying oceans affects the low-frequency variability of the fully coupled climate system. We argue that a better understanding of intrinsic SLA variability from such eddying simulations will also help interpreting the present 20 -yr altimetric observed dataset, as the models tend to get more accurate and closer to these data.

Acknowledgments. The authors acknowledge the constructive comments made by three anonymous reviewers, which led to a significant improvement of this paper. This work is a contribution to CHAOCEAN, OCCIPUT, and MyOcean2 projects. It benefited from the Drakkar international coordination network (GDRI) established between the Centre National de la Recherche Scientifique (CNRS), the National Oceanography Centre in Southampton (NOCS), GEOMAR in Kiel, and IFREMER. For this work, Drakkar also benefited from a grant from the Groupe Mission Mercator Coriolis (GMMC) through the LEFE program of the Institut National des Sciences de l'Univers (INSU). CHAOCEAN is supported by the Centre National d'Études Spatiales (CNES) through the Ocean Surface Topography Science Team (OST/ST). OCCIPUT is supported by the Agence Nationale de la Recherche (ANR) through Contract ANR-13-BS06-0007-01. The research leading to these results has received funding from the European Community's 160 Seventh Framework Programme FP7/2007-2013 under Grant Agreement 283367 (MyOcean2). The computations presented in this study were performed at the Centre Informatique National de l'Enseignement Supérieur (CINES) under the allocation made by GENCI x2013010727. The ORCA12-GJM02 simulation was performed as part of the Grands Challenges GENCI/CINES 2013. The altimeter products were produced by SSALTO/DUACS and distributed by AVISO, with support from CNES. GS is supported by CNES and Région Midi-Pyrénées, TP is supported by CNRS, SG by MyOcean2, and LT is supported by CERFACS.

\section{REFERENCES}

Arbic, B. K., R. B. Scott, G. R. Flierl, A. J. Morten, J. G. Richman, and J. F. Shriver, 2012: Nonlinear cascades of surface oceanic geostrophic kinetic energy in the frequency domain. J. Phys. Oceanogr., 42, 1577-1600, doi:10.1175/ JPO-D-11-0151.1.

— M. Müller, J. G. Richman, J. F. Shriver, A. J. Morten, R. B. Scott, G. Sérazin, and T. Penduff, 2014: Geostrophic turbulence in the frequency-wavenumber domain: Eddy-driven lowfrequency variability. J. Phys. Oceanogr., 44, 2050-2069, doi:10.1175/JPO-D-13-054.1.

Barnier, B., and Coauthors, 2006: Impact of partial steps and momentum advection schemes in a global ocean circulation model at eddy-permitting resolution. Ocean Dyn., 56 (5-6), 543-567, doi:10.1007/s10236-006-0082-1.

Berloff, P. S., A. M. Hogg, and W. Dewar, 2007: The turbulent oscillator: A mechanism of low-frequency variability of the wind-driven ocean gyres. J. Phys. Oceanogr., 37, 2363-2386, doi:10.1175/JPO3118.1.

Blanke, B., and P. Delecluse, 1993: Variability of the tropical Atlantic Ocean simulated by a general circulation model with two different mixed-layer physics. J. Phys. Oceanogr., 23, 1363-1388., doi:10.1175/1520-0485(1993)023<1363:VOTTAO > 2.0.CO;2.

Brachet, S., F. Codron, Y. Feliks, M. Ghil, H. Le Treut, and E. Simonnet, 2012: Atmospheric circulations induced by a midlatitude SST front: A GCM study. J. Climate, 25, 18471853, doi:10.1175/JCLI-D-11-00329.1.

Brodeau, L., B. Barnier, A.-M. Treguier, T. Penduff, and S. Gulev, 2010: An ERA40-based atmospheric forcing for global ocean circulation models. Ocean Modell., 31 (3-4), 88-104, doi:10.1016/j.ocemod.2009.10.005.

Bryan, F. O., 2013: Introduction: Ocean modeling-Eddy or not. Ocean Modeling in an Eddying Regime, Geophys. Monogr., Vol. 177, Amer. Geophys. Union, 1-3.

Charney, J. G., 1947: The dynamics of long waves in a baroclinic westerly current. J. Meteor., 4, 136-162, doi:10.1175/ 1520-0469(1947)004<0136:TDOLWI>2.0.CO;2.

Cleveland, W. S., and S. J. Devlin, 1988: Locally weighted regression: An approach to regression analysis by local fitting. J. Amer. Stat. Assoc., 83, 596-610, doi:10.1080/ 01621459.1988.10478639.

Combes, V., and E. Di Lorenzo, 2007: Intrinsic and forced interannual variability of the Gulf of Alaska mesoscale circulation. Prog. Oceanogr., 75, 266-286, doi:10.1016/ j.pocean.2007.08.011.

Deshayes, J., and Coauthors, 2013: Oceanic hindcast simulations at high resolution suggest that the Atlantic MOC is bistable. Geophys. Res. Lett., 40, 3069-3073, doi:10.1002/ grl.50534.

Dewar, W. K., 2003: Nonlinear midlatitude ocean adjustment. J. Phys. Oceanogr., 33, 1057-1082, doi:10.1175/1520-0485(2003)033<1057: $\mathrm{NMOA}>2.0 . \mathrm{CO} ; 2$.

Dijkstra, H. A., and M. Ghil, 2005: Low-frequency variability of the large-scale ocean circulation: A dynamical systems approach. Rev. Geophys., 43, RG3002, doi:10.1029/2002RG000122.

Douglass, E. M., S. R. Jayne, F. O. Bryan, S. Peacock, and M. Maltrud, 2012: Kuroshio pathways in a climatologically forced model. J. Oceanogr., 68, 625-639, doi:10.1007/ s10872-012-0123-y.

_, Y.-O. Kwon, and S. R. Jayne, 2013: A comparison of North Pacific and North Atlantic subtropical mode waters in a climatologically-forced model. Deep-Sea Res. II, 91, 139-151, doi:10.1016/j.dsr2.2013.02.023.

Duchon, C., 1979: Lanczos filtering in one and two dimensions. J. Appl. Meteor., 18, 1016-1022, doi:10.1175/ 1520-0450(1979)018<1016:LFIOAT > 2.0.CO;2.

Dussin, R., and B. Barnier, 2013: The making of DFS 5.1. Drakkar Project Rep., 40 pp. [Available online at http://www.drakkarocean.eu/publications/reports/dfs5-1-report.]

Eady, E. T., 1949: Long waves and cyclone waves. Tellus, 1, 33-52, doi:10.1111/j.2153-3490.1949.tb01265.x. 
Greatbatch, R. J., 1994: A note on the representation of steric sea level in models that conserve volume rather than mass. J. Geophys. Res., 99 (C6), 12 767-12 771, doi:10.1029/94JC00847.

Grégorio, S., T. Penduff, G. Sérazin, J.-M. Molines, B. Barnier, and J. Hirschi, 2015: Intrinsic variability of the Atlantic Meridional Overturning Circulation at interannual-to-multidecadal timescales. J. Phys. Oceanogr., in press. doi:10.1175/JPO-D-14-0163.1.

Gulev, S. K., M. Latif, N. Keenlyside, W. Park, and K. P. Koltermann, 2013: North Atlantic Ocean control on surface heat flux on multidecadal timescales. Nature, 499, 464-467, doi:10.1038/ nature12268.

Hazeleger, W., and S. S. Drijfhout, 2000: A model study on internally generated variability in subtropical mode water formation. J. Geophys. Res., 105 (C6), 13 965, doi:10.1029/ 2000JC900041.

Holland, W. R., 1978: The role of mesoscale eddies in the general circulation of the ocean-numerical experiments using a wind-driven quasi-geostrophic model. J. Phys. Oceanogr., 8, 363-392, doi:10.1175/1520-0485(1978)008<0363: TROMEI $>2.0 . \mathrm{CO} ; 2$.

Hurlburt, H. E., and Coauthors, 2009: High-resolution global and basin-scale ocean analyses and forecasts. Oceanography, 22, 110-127, doi:10.5670/oceanog.2009.70.

Le Sommer, J., T. Penduff, S. Theetten, G. Madec, and B. Barnier, 2009: How momentum advection schemes influence current-topography interactions at eddy permitting resolution. Ocean Modell., 29, 1-14, doi:10.1016/ j.ocemod.2008.11.007.

Madec, G., 2008: NEMO ocean engine. Institut Pierre-Simon Laplace (IPSL) Note du Pole de Modélisation 27, 217 pp.

Molines, J.-M., B. Barnier, T. Penduff, A. M. Treguier, and J. Le Sommer, 2014: ORCA12.L46 climatological and interannual simulations forced with DFS4.4: GJM02 and MJM88. Drakkar Group Experiment Rep. GDRI-DRAKKAR-2014-03-19, 50 pp. [Available online at http://www.drakkar-ocean.eu/ publications/reports/orca12_reference_experiments_2014.]

O'Kane, T. J., R. J. Matear, M. A. Chamberlain, J. S. Risbey, B. M. Sloyan, and I. Horenko, 2013: Decadal variability in an OGCM Southern ocean: Intrinsic modes, forced modes and metastable states. Ocean Modell., 69, 1-21, doi:10.1016/ j.ocemod.2013.04.009.

Okkonen, S. R., G. A. Jacobs, E. Joseph Metzger, H. E. Hurlburt, and J. F. Shriver, 2001: Mesoscale variability in the boundary currents of the Alaska gyre. Cont. Shelf Res., 21 (11-12), 12191236, doi:10.1016/S0278-4343(00)00085-6.

Penduff, T., J. Le Sommer, B. Barnier, A.-M. Treguier, J.-M. Molines, and G. Madec, 2007: Influence of numerical schemes on current-topography interactions in $1 / 4^{\circ}$ global ocean simulations. Ocean Sci., 3, 509-524, doi:10.5194/os-3-509-2007.

—, M. Juza, L. Brodeau, G. C. Smith, B. Barnier, J.-M. Molines, A.-M. Treguier, and G. Madec, 2010: Impact of global ocean model resolution on sea-level variability with emphasis on interannual time scales. Ocean Sci., 6, 269-284, doi:10.5194/ os-6-269-2010.

—_ — - B. Barnier, J. Zika, W. K. Dewar, A.-M. Treguier, J.-M. Molines, and N. Audiffren, 2011: Sea level expression of intrinsic and forced ocean variabilities at interannual time scales. J. Climate, 24, 5652-5670, doi:10.1175/ JCLI-D-11-00077.1.

Pierini, S., 2006: A Kuroshio Extension system model study: Decadal chaotic self-sustained oscillations. J. Phys. Oceanogr. 36, 1605-1625, doi:10.1175/JPO2931.1.

- 2011: Low-frequency variability, coherence resonance, and phase selection in a low-order model of the wind-driven ocean circulation. J. Phys. Oceanogr., 41, 1585-1604, doi:10.1175/ JPO-D-10-05018.1.

_ 2014: Kuroshio Extension bimodality and the North Pacific Oscillation: A case of intrinsic variability paced by external forcing. J. Climate, 27, 448-454, doi:10.1175/JCLI-D-13-00306.1.

Quattrocchi, G., S. Pierini, and H. A. Dijkstra, 2012: Intrinsic lowfrequency variability of the Gulf Stream. Nonlinear Processes Geophys., 19, 155-164, doi:10.5194/npg-19-155-2012.

Simonnet, E., and H. A. Dijkstra, 2002: Spontaneous generation of low-frequency modes of variability in the wind-driven ocean circulation. J. Phys. Oceanogr., 32, 1747-1762, doi:10.1175/ 1520-0485(2002)032<1747:SGOLFM $>2.0 . \mathrm{CO} ; 2$.

Spall, M. A., 1996: Dynamics of the Gulf Stream/deep western boundary current crossover. Part II: Low-frequency internal oscillations. J. Phys. Oceanogr., 26, 2169-2182, doi:10.1175/ 1520-0485(1996)026<2169:DOTGSW > 2.0.CO;2.

Taguchi, B., S.-P. Xie, N. Schneider, M. Nonaka, H. Sasaki, and Y. Sasai, 2007: Decadal variability of the Kuroshio Extension: Observations and an eddy-resolving model hindcast. J. Climate, 20, 2357-2377, doi:10.1175/JCLI4142.1.

Thomas, M. D., and X. Zhai, 2013: Eddy-induced variability of the meridional overturning circulation in a model of the North Atlantic. Geophys. Res. Lett., 40, 2742-2747, doi:10.1002/ grl.50532.

Thompson, A. F., and K. J. Richards, 2011: Low frequency variability of Southern Ocean jets. J. Geophys. Res., 116, C09022, doi:10.1029/2010JC006749.

Treguier, A. M., and Coauthors, 2014: Meridional transport of salt in the global ocean from an eddy-resolving model. Ocean Sci., 10, 243-255, doi:10.5194/os-10-243-2014. 